\title{
Stage I Intrahepatic Cholangiocarcinoma AJCC v8
}

National Cancer Institute

\section{Source}

National Cancer Institute. Stage I Intrahepatic Cholangiocarcinoma A/CC v8. NCI

Thesaurus. Code C134757.

Stage I includes: IA (T 1a, N0, M0); IB (T 1b, N0, M0). T1a: Solitary tumor equal or less than $5 \mathrm{~cm}$ without vascular invasion. T1 b: Solitary tumor larger than $5 \mathrm{~cm}$ without vascular invasion. N0: No regional lymph node metastasis. M0: No distant metastasis. (AJCC 8th ed.) 